University of Nebraska - Lincoln

DigitalCommons@University of Nebraska - Lincoln

2-7-2019

\title{
Autodissemination of pyriproxyfen as a method for controlling the house fly Musca domestica
}

\author{
Haim Biale \\ University of Haifa, Biale.h@gmail.com \\ Elad Chiel \\ University of Haifa-Oranim \\ Christopher J. Geden \\ USDA, ARS, Chris.geden@ars.usda.gov
}

Follow this and additional works at: https://digitalcommons.unl.edu/usdaarsfacpub

Biale, Haim; Chiel, Elad; and Geden, Christopher J., "Autodissemination of pyriproxyfen as a method for controlling the house fly Musca domestica" (2019). Publications from USDA-ARS / UNL Faculty. 2141. https://digitalcommons.unl.edu/usdaarsfacpub/2141

This Article is brought to you for free and open access by the U.S. Department of Agriculture: Agricultural Research Service, Lincoln, Nebraska at DigitalCommons@University of Nebraska - Lincoln. It has been accepted for inclusion in Publications from USDA-ARS / UNL Faculty by an authorized administrator of DigitalCommons@University of Nebraska - Lincoln. 


\title{
Autodissemination of pyriproxyfen as a method for controlling the house fly Musca domestica
}

\author{
Haim Biale ${ }^{1} \mathbb{D} \cdot$ Elad Chiel $^{2} \cdot$ Christopher J. Geden $^{3}$
}

Received: 11 October 2018 / Revised: 24 January 2019 / Accepted: 2 February 2019 / Published online: 7 February 2019

(c) Springer-Verlag GmbH Germany, part of Springer Nature 2019

\begin{abstract}
House fly (Musca domestica) control is a major challenge in animal agriculture. Here, we tested the feasibility of applying pyriproxyfen (PPF), an insect-growth regulator that controls house flies effectively, using autodissemination methods, in which the flies themselves deliver PPF to their oviposition sites. First, we tried baiting gravid female flies to walk-through stations, where flies would self-treat with PPF and distribute it. This concept worked well in laboratory and indoor cage experiments, but not in the field, as flies appeared reluctant to alight on and collect PPF. Therefore, we tested a different concept of actively coating flies with PPF and then releasing them in different proportions. This concept was tested in laboratory experiments with various manure types in the USA and in Israel. Twenty percent of PPF-coated flies (corresponding to $\geq 2.3 \mathrm{mg} / \mathrm{kg}$ PPF) were sufficient to get high control levels $(\sim 90 \%)$ in most of the tested manure types in the US study. Very similar results were obtained in the experiments in Israel but only with poultry manure, whereas low control levels were obtained when cow manure was used. We conclude that autodissemination of PPF using the collect-treat-release "active coating" concept may be practical, depending on manure type, and should be further tested in the field.
\end{abstract}

Keywords Insect-growth regulator $\cdot$ Integrated pest management $\cdot$ Animal manure

\section{Key messages}

- We examined the feasibility of applying pyriproxyfen using autodissemination methods for controlling the house fly.

Communicated by C. Cutler.

Electronic supplementary material The online version of this article (https://doi.org/10.1007/s10340-019-01092-x) contains supplementary material, which is available to authorized users.

Haim Biale

Biale.h@gmail.com

1 Department of Evolutionary and Environmental Biology, University of Haifa, Aba Khoushy Ave, Mount Carmel, 3498838 Haifa, Israel

2 Department of Biology and Environment, University of Haifa-Oranim, 3600600 Qiryat Tivon, Israel

3 Center for Medical, Agricultural, and Veterinary Entomology, USDA, ARS, 1600 SW 23rd Drive, Gainesville, FL 32608, USA
- High control levels were achieved in most of the manure types tested in the USA, whereas in the experiments in Israel high control levels were obtained only in poultry manure.

- Treating $10-20 \%$ of females (resulting in $2.3-4.8 \mathrm{mg} / \mathrm{kg}$ PPF in target substrates) was sufficient to achieve control in most of the manure types tested in the USA and poultry manure in Israel.

- Luring house flies to pyriproxyfen-collecting stations in the field was not effective enough with the devices tested.

- Autodissemination may be practical, depending on manure type and proportion of treated flies.

\section{Introduction}

The house fly, Musca domestica L. (Diptera: Muscidae), is a major pest of animal agriculture and human waste management systems, vectoring numerous pathogens, causing serious nuisance and often impairing the productivity of farm animals (Malik et al. 2007). Annual economic losses due to this pest in the USA are estimated at hundreds of millions of dollars (Geden and Hogsette 2001). House 
flies have a high reproductive capacity where each female can lay hundreds of eggs, and more than 20 generations may develop annually in subtropical and tropical regions (Sanchez-Arroyo and Capinera 2014). In order to control this pest effectively, an integrated pest management (IPM) approach is required, including manure management, biological control and selective use of insecticides (Farkas et al. 2000; Durel et al. 2015). However, due to the rapid development of insecticide-resistance to new products with novel modes of action, insecticidal control of house flies has become increasingly difficult (Malik et al. 2007; Kaufman et al. 2010; Khan et al. 2013; Kasai et al. 2017; Scott 2017). For example, in a recent survey house flies were found to be highly resistant to permethrin and methomyl, but less so to tetrachlorvinphos, cyfluthrin and others (Scott et al. 2013). One of the insecticides that is still effective and has commercial products available for controlling house flies, at least in some countries, is pyriproxyfen (PPF) - a broadspectrum juvenile hormone analog that inhibits metamorphosis and embryogenesis in several insect orders (Ishaaya and Degheele 1998; Tunaz 2004; Bensebaa et al. 2015). In the house fly, like other dipterans, PPF inhibits pupal-adult metamorphosis (Geden and Devine 2012).

Recently, we showed that PPF is effective against wild populations of house flies in Israel and the USA when tested on wheat bran-based fly rearing medium in the laboratory, and less effective on cow manure (Biale et al. 2017). Additionally, we found that PPF is compatible with principal house fly parasitoids and is therefore suitable for use in IPM (Biale et al. 2017). Application of PPF by spreading granules or spraying a liquid solution can be costly, labor-intensive, has unintended harmful effects on non-target organisms, and may miss fly breeding spots. An alternative is the autodissemination approach, in which treated gravid females would deliver PPF to oviposition sites. Such an approach would have several advantages: (1) The amount of pyriproxyfen required would be reduced, thus lowering costs; (2) the use of gravid females to target oviposition sites could improve control in hard-to-access breeding areas; and (3) a reduction in negative effects on the environment and beneficial insects.

The autodissemination method has received the most attention in systems using entomopathogenic fungi on beetles (e.g., Klein and Lacey 1999; Dowd and Vega 2003; Moslim et al. 2011), or moths (e.g., Furlong et al. 1995; Vickers et al. 2004; El-Sufty et al. 2011). Recently, it has been shown that PPF can be disseminated to the aquatic habitats of mosquitoes by the adult females themselves, both in the laboratory (Gaugler et al. 2012; Tuten et al. 2016) and field (Devine et al. 2009; Caputo et al. 2012; Unlu et al. 2017). In this autodissemination approach, adult female mosquitoes were lured to stations containing baits with PPF, where they pick up PPF on their body and subsequently transport it to their egg-laying sites. The result is a targeted delivery of a larval control product restricted to the stage and place where it is needed (Devine et al. 2009). Geden and Devine (2012) demonstrated that the autodissemination concept can be similarly implemented with house flies by using the adults for transporting PPF to egg-laying substrates, resulting in reduced emergence rates from the pupal stage. Based on those observations, we hypothesized that the autodissemination method with PPF can be efficient for controlling the house fly; however, we predicted that the observations in the laboratory would be much better than those in the field due to technic, biotic and abiotic factors. Moreover, based on our study with different media (Biale et al. 2017), we predicted the autodissemination method to be more/less efficient with different types of manures.

The broad objective of this study was to test the efficacy and feasibility of autodissemination methods with PPF for controlling house flies in laboratory and later in the field.

\section{Materials and methods}

\section{House fly sources and rearing}

Tests were conducted in the USA and Israel using three strains of flies. Most of the USA tests were done with a long-established insecticide-susceptible strain ("Orlando Normal") that has been maintained without insecticide selection since its establishment in the early 1950s. An additional wild-type colony was used in one of the experiments. This colony was formed in 2015 by mixing wild flies collected from dairy farms in Nebraska, California, Minnesota and Florida. Tests in Israel were done with a house fly strain that was established from flies collected on a dairy farm in Sde-Ya'akov (32 41'32.4"N 3508'32.0"E) during 2017. Flies were reared under similar conditions and methods in both the USA and in Israel. Adults were held in net cages with an ample supply of water and a diet of sugar, milk powder and egg yolk powder mixture, in a ratio of $8: 8: 1$ by volume, respectively. The larvae were reared on a 13:1 mixture (by volume) of wheat bran and calf feed pellets (main ingredients: corn, wheat and barley seeds with soy, canola or sunflower mill), wetted with water to $60-65 \%$ moisture. Flies were maintained at $26-28{ }^{\circ} \mathrm{C}, 50-80 \% \mathrm{RH}$, and $14: 10$ light/dark photoperiod.

\section{Persistence of PPF on treated flies}

Initially, various high-potency PPF dusts were formulated and tested for their suitability for use in the autodissemination approach for house flies (see the supplementary material for full details). Based on these results, we chose a formulation (termed "CMAVE1") that contained oil and was easier to work with and less prone to being scattered by air 
currents. This formulation was composed of $5 \mathrm{~g}$ technical PPF, $800 \mu$ of corn oil, $4.5 \mathrm{~g}$ Safer@ diatomaceous earth (Woodstream, Lititz, PA) and $12 \mathrm{ml}$ acetone (to dissolve the $\mathrm{PPF})$. The mixture was dried for $24 \mathrm{~h}$ before being used to allow the acetone to evaporate, resulting in a powder with $48.5 \%$ PPF.

Two experiments were conducted to determine whether PPF-treated flies would retain enough material to be effective several hours after exposure. In the first test, groups of five gravid female flies (Orlando Normal strain) were compelled to walk along a $22-\mathrm{cm}$ tube lined with a mesh treated with the PPF formulation. The mesh material was a coarsely woven polyester tulle fabric obtained from Joann Fabric and Craft (https://www.joann.com). The mesh was treated by first brushing it lightly with cotton balls dipped in corn oil, shaking in a sealed bag with PPF dust and shaking to remove surplus dust. Five-to-ten min was required for all the flies to traverse the length of the tubes. Each tube's exit was placed on a cage opening, and the tube was removed once all five flies had entered the cage. The cages were not supplied with food or water. Cups of fly larval rearing medium were added to the cages at either time zero (immediately after the final fly entered) or 1,3 or $6 \mathrm{~h}$ after exposure to the dust. Cups containing medium were removed $24 \mathrm{~h}$ later and held for pupation and fly emergence. Controls consisted of flies that walked through an untreated tube and were presented with cups and medium $6 \mathrm{~h}$ later.

In the second experiment, mesh treated with PPF was cut into disks and placed in the bottom of a 100-mm-diameter Petri dish. A 20-mm-diameter disk of untreated plastic was placed on top of the mesh. Groups of five gravid flies were briefly anesthetized with $\mathrm{CO}_{2}$ and then placed on the untreated plastic disk at the first sign of recovery. The lid was placed on the dish, the dish was transferred to a cage, and the flies were allowed to move about the dish for three min. The lid was then removed to release the flies, and the Petri dish with treated mesh was removed from the cage. Cups containing fly larval rearing medium were placed in the cages 1 and $6 \mathrm{~h}$ after exposure of the flies to the PPF dust. Half of the cages were provided with food and water at the outset, and half were not so that both time points included cages with and without food and water. Cups containing medium were removed $24 \mathrm{~h}$ after they were placed in the cages and held at $27{ }^{\circ} \mathrm{C}$ for pupation. Pupae were separated from the media by water floatation, dried, and adult flies were counted after emergence. Both experiments were replicated three times.

\section{Autodissemination tests}

Autodissemination tests were conducted in large indoor cages and in the field. Indoor tests were conducted in cages that were $1.3 \mathrm{~m}$ on each side. Fifty gravid females were added to each cage along with a Captivator fly trap
(Central Life Sciences, Council Bluffs, IA) with its respective attractant bait and a $12-\mathrm{cm}$ square of mesh treated with PPF dust attached to the trap opening with a rubber band. After $6 \mathrm{~h}$, each cage was provisioned with four pails containing 41 of wheat bran fly larval medium. After an additional $12 \mathrm{~h}$, the flies in each cage were given food (powdered milk, sugar, powdered egg in a 6:6:1 ratio) and water. The pails of medium were removed after $24 \mathrm{~h}$ and held for fly development and emergence. The experiment was conducted on three occasions using two PPF-treated cages and one control cage.

The first field test was conducted at two locations at a dairy farm near Beatrice, Nebraska. At the first location, pre-treatment bioassays were done by placing four pans $(56 \times 44 \times 7.5 \mathrm{~cm})$ containing 81 of a medium that was a $3: 1$ mixture of fly larval rearing medium and cow manure in an empty calf pen. The empty calf pen was next to occupied pens and had high levels of adult house fly activity (based in visual observation). Pans were removed after $12 \mathrm{~h}$. Three Captivator traps with PPF-treated mesh covers were then placed in the pen (for more details, see the figure in the supplementary material). After an additional $12 \mathrm{~h}$, four new pans of rearing medium/manure were placed in the pen with the traps and left for $24 \mathrm{~h}$. Then, the pans were brought to the laboratory, covered with pillow cases and held for fly development and emergence. The second Nebraska location was outdoors near a manure-solids separator, and pans and PPF devices were placed in the same manner. The fly population in this area was low to moderate.

Oviposition in the pans was variable and sometimes resulted in severe larval crowding several days after collection. When this was the case, pans were split on day 4 and fresh medium was added to ensure successful development.

The second field test was conducted at a California dairy farm near San Jacinto in September 2016. Conditions were dry and hot, and fly populations were low (based on visual observation). The test was conducted in the same manner as described for the Nebraska tests, except that a different PPF delivery method was used. Rather than using treated mesh over a jar trap, devices were fabricated using an inverted screen cone design with a pan of Central Life Science (=Farnam) fly bait at the base of the cone. Flies could enter the cone from below (over the surface of the bait). At the top of the cone was placed a paper cylinder lined with PPF dust-treated orthopedic stockinette that flies would cross to escape the device from the top. The cone was surrounded by a cut-out 5 -gallon plastic pail that provided a surrounding structure. This allowed wrapping the structure with blue fabric and placing a blue cover over the top that covered the device except for the exit tube containing the PPF (Fig. 1). The intent was for flies to be attracted to the bait, enter the cone and orient upward toward the light coming through the treated paper tube. Three PPF devices and four sets of 


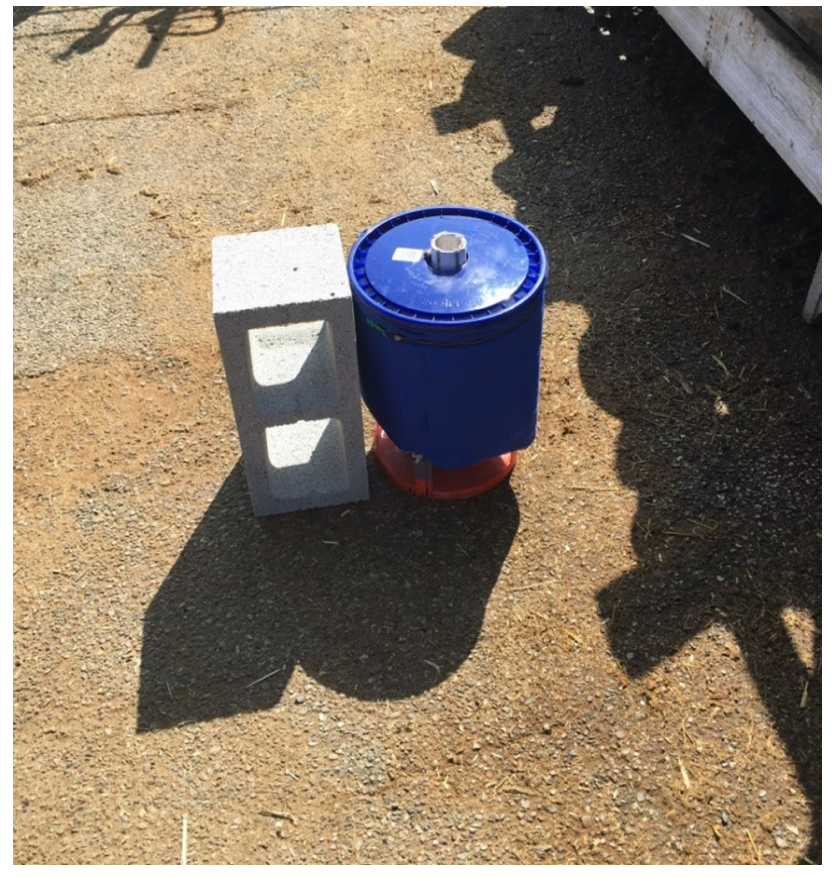

Fig. 1 Designs of pyriproxyfen (PPF) autodissemination stations for house flies tested on dairy farms in California. The devices were composed of inverted cones placed over pans of fly bait with the top of cone removed to allow flies to pass through a cylinder lined with PPF-treated fabric. The cone was shrouded with dark fabric and covered with a plastic lid to encourage flies that entered the cone to move upwards toward the light and through the treated tube

pre- and post-treatment pans of rearing medium/manure were placed on the farm in areas with visible fly activity.

\section{Varying the proportion of treated flies on different media}

Several tests were conducted in which different fly larval media and the proportion of PPF-treated flies were varied. The PPF formulation used in these experiments was a modification of the CMAVE1 formulation and was composed of $1.5 \mathrm{~g}$ PPF, $6 \mathrm{ml}$ acetone, $300 \mu \mathrm{l}$ soy oil and $2.5 \mathrm{~g}$ of diatomaceous earth ( $35 \%$ final PPF concentration). This formulation was chosen after additional sets of formulations were compared (see full details in the supplementary material).

In the first test, conducted with Orlando Normal flies, gravid female flies were held for five min in a Petri dish that contained PPF-treated mesh, and then briefly anesthetized and placed on the surface of $1.4 \mathrm{~kg}$ of wheat bran medium in 2-1 plastic containers which were covered with muslin cloth, along with untreated flies to form groups of 20 flies that included $1,2,5$ or 10 treated flies $(5,10,25$ and $50 \%$, respectively). Treated and untreated flies were added separately, so that there would be no contamination of untreated flies with PPF during the experimental setup. A 3-cm-diameter ball of cow manure was placed on top of the medium to encourage oviposition. Groups of 20 untreated flies served as controls. After $24 \mathrm{~h}$, the flies were removed from the containers and the containers were held at $27{ }^{\circ} \mathrm{C}$ for fly development and emergence. There were three replications of each combination of treated flies. Flies were weighed before, immediately after, and at the end of the 24-h test period. Samples of flies were weighed before, immediately after treatment, and at the end of the 24-h test period. Treated flies acquired $2.2-4.8 \mathrm{mg}$ of powder/fly and appeared to have lost most of the payload at the end of the test period. This allowed calculation of an estimate of the amount of PPF in the media visited by the flies.

In the second experiment, different animal manures (cow, horse and caged-layer poultry) were collected from Florida or Georgia (USA) farms that were not using any insecticides, and frozen for at least one week to kill any arthropods present. Moisture content of the collected cow, horse and poultry was 72,75 and $62 \%$, respectively. Manure of each type was thawed, and $350 \mathrm{~g}$ was placed in $500 \mathrm{~cm}^{3}$ plastic cups, which were covered with muslin cloth. Wheat bran larval diet was also prepared and placed in cups for comparison. Gravid female flies from the US wild-type colony were treated by a 1 -min exposure in $60-\mathrm{ml}$ glass jars containing $1 \mathrm{~g}$ of PPF powder. Treated flies were anesthetized with $\mathrm{CO}_{2}$, any surplus dust on the flies was tapped off, and then, the flies were placed on the surface of the manure or medium along with untreated female flies to form groups of five flies that included 0,1 or 3 treated flies $(0,20$ and $60 \%$ treated flies, respectively). After $24 \mathrm{~h}$, the flies were removed from the containers and the containers were held at $27{ }^{\circ} \mathrm{C}$ for fly development. Larvae were reared in until pupation, pupae were then isolated from the rearing medium by water floatation, and 100 pupae from each cup were incubated for adult emergence, and the emerging adults were counted. There were three replications of each combination for each manure type.

The third experiment was similar to the second but conducted with Israeli flies and manures. Cow and caged-layer poultry manures were collected from Israeli farms that were not using any insecticides during previous months, and frozen as before. Manure of each type was thawed, and $350 \mathrm{~g}$ was placed in $500 \mathrm{~cm}^{3}$ cups as mention above. Wheat bran larval diet was also prepared and placed in cups for comparison. Gravid females from the Israeli fly colony were gently shaken for $30 \mathrm{~s}$ in a Petri dish containing the PPF powder. Then, groups of 10 gravid females were placed in each cup, of which either $0,1,2,5$ or 10 females were coated with PPF. Treated and untreated flies were added separately so that there would be no contamination of untreated flies with PPF during the experimental setup. Females were allowed to oviposit for $24 \mathrm{~h}$, and then removed from the cups. Larvae were reared in until pupation, pupae were then isolated from the rearing 
medium by water floatation, counted and incubated for adult emergence, and the emerging adults were counted. There were five replications of each combination of treated flies.

The final experiment examined the effects of dusting flies and releasing them into cages prior to oviposition rather than placing them directly on manure. Israeli cow and caged-layer poultry manures were collected and treated as described above, then portions of $350 \mathrm{~g}$ were divided into $500 \mathrm{~cm}^{3}$ cups, which were placed in plastic cages $(24.5 \times 27 \times 17 \mathrm{~cm})$ covered with plastic mesh. Groups of 20 gravid female flies, of which either 0,4 or 10 females (in poultry manure, a treatment of two females was included as well) were coated with PPF formulation as described above and placed in each cage. (No food or water was added.) Flies were allowed to oviposit for $24 \mathrm{~h}$, and then removed, and the manure cups were held for larval development until pupation. Pupae were collected and held for adult emergence as in the previous tests. There were at least five cages of each combination of treated flies. The two experiments described above were held in incubators at $26 \pm 1^{\circ} \mathrm{C}$ and 14:10 L:D light regime.

\section{Statistical analyses}

Data for most experiments were analyzed by one-way ANOVA using either the Statistical Analysis System (SAS version 9.2, SAS Institute, Cary, NC) or SPSS 19/24 (IBM SPSS statistics, Chicago, IL, USA), using Tukey's method to separate treatment means. Prior to ANOVA, data on fly mortality from pupa to adult were tested for normality with the Shapiro-Wilk and Kolmogorov-Smirnov methods using the Univariate Procedure of SAS/SPSS. Data were subjected to arcsine or $\log$ transformation and re-analyzed in those instances where untransformed values did not meet the normality standard. When non-normality (Shapiro-Wilk test) or inequality of error variances (Levene's test) was detected even after transformations, nonparametric tests (Kruskal-Wallis followed by Mann-Whitney) were used instead of ANOVA. Data on fly emergence for the field tests were analyzed by two-way ANOVA using before/after PPF device placement and location (indoor calf pen/outdoor area) as main effects in a randomized complete block design in SAS, with four observations (pans) per treatment. Data on the effect of varying manure type and the proportion of PPF-treated flies were analyzed by two-way ANOVA with interaction in SAS using manure type and the proportion of PPF-treated flies as the main effects.

\section{Results}

\section{Persistence of PPF on treated flies}

When gravid female flies traversed a PPF-treated mesh tube into a cage with no food or water and were given an opportunity to oviposit at different times after exposure, significantly higher pupal mortality was observed among PPFtreated flies than controls at all time points, with pupal mortality of 95.6-100\% compared with $6.1 \%$ for controls (data not shown) $(F=261.6 ; P<0.01)$. There were no significant mortality differences among any of the PPF treatments (flies held $0,1,3$ and $6 \mathrm{~h}$ after treatment). When gravid female flies were given a brief ( $3 \mathrm{~min}$ ) exposure to PPF-treated mesh in a Petri dish, pupal mortality was highest ( 93\%) when flies were allowed to oviposit $1 \mathrm{~h}$ after exposure to PPF, and mortality was lower $(\sim 70 \%)$ after a 6-h holding interval after treatment (Table 1). Pupal mortality in all PPF treatments was significantly higher than the controls and was unaffected by the presence or absence of food and water in the cages with PPF-treated flies.

\section{Autodissemination tests}

When groups of 50 gravid female flies were exposed to baited PPF autodissemination devices on a free-choice basis in indoor cages, pupal mortality was significantly higher in the PPF-treatment $(81.0 \%)$ than in the controls (6.0\%) $(F=29.31 ; P<0.01)$ (data not shown). In the field, pupal production from pans placed before and after deployment of PPF devices on a Nebraska dairy farm did not differ significantly (13,433 and 11,065 pupae per pan, respectively). Pupal mortality rates were slightly higher after than before placement of PPF devices, but the difference was small (29.8 and $17.7 \%$, respectively) $(F=5.55$; $P<0.05)$ (data not shown). In the test on the California dairy, pupal numbers were substantially lower than in the Nebraska trial (ca. 1000 pupae per pan), and there was no significant difference in pupal mortality before and after placement of the PPF devices $(F=0.32 ; P>0.05)$

Table 1 Effect of a brief exposure of gravid female house flies to PPF on pupal mortality ${ }^{1}$

\begin{tabular}{lll}
\hline $\begin{array}{l}\text { Time (h) after PPF } \\
\text { exposure }\end{array}$ & $\begin{array}{l}\text { Mean (SE) \% pupal mortality of progeny } \\
\text { from flies }\end{array}$ \\
\cline { 2 - 3 } & $\begin{array}{l}\text { Provided with food and } \\
\text { water }\end{array}$ & $\begin{array}{l}\text { Not provided } \\
\text { with food and } \\
\text { water }\end{array}$ \\
\hline 0 (controls) & - & $16.5(4.5) \mathrm{a}$ \\
1 & $93.7(3.2) \mathrm{b}$ & $93.0(4.0) \mathrm{b}$ \\
6 & $69.9(5.6) \mathrm{c}$ & $69.3(6.4) \mathrm{c}$ \\
\hline
\end{tabular}

${ }^{1}$ Flies were treated allowing them to walk on mesh treated with PPF dust for $3 \mathrm{~min}$, then released into cages and presented with fresh wheat bran larval medium for oviposition at different times postexposure. Flies either provided with food and water or not in the $h$ after exposure

${ }^{2}$ Means followed by the same letter are not significantly different at $P=0.05$ (Tukey's HSD) 
(data not shown). Observations of fly behavior around the devices indicated that very few flies actually landed on or went through the Nebraska or California autodissemination devices.

Table 2 Effect of varying the proportion of PPF-treated (by forced contact) female house flies on pupal mortality, after flies were placed on wheat bran rearing medium for $24 \mathrm{~h}$ after exposure

\begin{tabular}{ll}
\hline No. PPF flies/total flies (mg/kg PPF range $)^{1}$ & $\begin{array}{l}\text { Mean (SE) } \\
\% \text { pupal } \\
\text { mortality }^{2}\end{array}$ \\
\hline $0 / 20($ no PPF) & $10.1(5.4) \mathrm{a}$ \\
$1 / 20(0.6-1.2 \mathrm{mg} / \mathrm{kg} \mathrm{PPF})$ & $52.6(5.9) \mathrm{b}$ \\
$2 / 20(1.2-2.4 \mathrm{mg} / \mathrm{kg} \mathrm{PPF})$ & $89.4(4.4) \mathrm{c}$ \\
$5 / 20(3-6 \mathrm{mg} / \mathrm{kg} \mathrm{PPF})$ & $93.5(3.9) \mathrm{c}$ \\
$10 / 20(6-12 \mathrm{mg} / \mathrm{kg} \mathrm{PPF})$ & $99.9(0.0) \mathrm{c}$ \\
$20 / 20(12-24 \mathrm{mg} / \mathrm{kg} \mathrm{PPF})$ & $100.0(0.0) \mathrm{c}$ \\
ANOVA $F$ & $79.38^{* *}$ \\
$d f=5,18 ; P<0.01$ & \\
\hline
\end{tabular}

${ }^{1}$ PPF concentration calculation: $0.8-1.7 \mathrm{mg}$ PPF carried by each fly, divided by the weight of the substrate, $1400 \mathrm{~g}$

${ }^{2}$ Means within column followed by the same letter are not significantly different at $P=0.05$ (Tukey's HSD)

\section{Varying the proportion of treated flies on different media}

Measurement of pre- and post-treatment weights of treated flies indicated that treated flies carried $2.2-4.8 \mathrm{mg}$ of powder each (data not shown). This enabled us to estimate the concentration of PPF in the different larval media in those experiments (Tables 2, 3 and 4).

When wheat bran larval diet was used as larval growth medium, pupal mortality was significantly higher among all PPF-treated groups than the controls (Table 2). Pupal mortality reached $50 \%$ mortality when only a single fly out of 20 (5\%) was treated with PPF dust, and was highest in groups of flies that included 2-20 treated flies out of 20 flies total (i.e., $\geq 1.2 \mathrm{mg} / \mathrm{kg}$ PPF in the substrate, based on the amount of powder carried by treated flies).

When different manure types were used as larval growth medium, the effect of the number of PPF-treated flies was significant, as was the interaction between manure type and proportion of treated flies (Table 3). Pupal mortality in tests that included one or three treated flies out of five flies total (i.e., $\geq 2.3 \mathrm{mg} / \mathrm{kg}$ PPF in the substrate) was $>89.9 \%$ in all substrates except horse manure (Table 3 ).

In the Israeli experiment using wheat bran medium, pupal mortality was generally lower than in the experiment with US flies, even in the groups where $100 \%$ of the females were treated with PPF (Table 4). In contrast, pupal mortality in cow and poultry manure was much higher when all of the
Table 3 Effect of varying the proportion of PPF-treated (by forced contact) female house flies on pupal mortality, after flies were placed on wheat bran rearing medium or different animal manures for $24 \mathrm{~h}$ after exposure. Flies were placed in groups of five, of which 0,1 or 3 flies were coated with PPF

\begin{tabular}{|c|c|c|}
\hline Substrate & No. PPF flies (mg/kg PPF range) ${ }^{1}$ & $\begin{array}{l}\text { Mean (SE) } \\
\% \text { pupal } \\
\text { mortality }^{2}\end{array}$ \\
\hline Bran medium & 0 (no PPF) & $5.2(1.2)$ \\
\hline Bran medium & $1(2.3-4.8 \mathrm{mg} / \mathrm{kg}$ PPF $)$ & $93.4(3.4)$ \\
\hline Bran medium & $3(6.9-14.4$ mg/kg PPF) & $99.2(0.8)$ \\
\hline Cow manure & 0 (no PPF) & $7.6(4.9)$ \\
\hline Cow manure & $1(2.3-4.8 \mathrm{mg} / \mathrm{kg} \mathrm{PPF})$ & $95.4(2.2)$ \\
\hline Cow manure & 3 (6.9-14.4 mg/kg PPF) & $98.6(1.2)$ \\
\hline Horse manure & 0 (no PPF) & $4.6(1.2)$ \\
\hline Horse manure & $1(2.3-4.8 \mathrm{mg} / \mathrm{kg} \mathrm{PPF})$ & $56.4(10.0)$ \\
\hline Horse manure & 3 (6.9-14.4 mg/kg PPF) & $98.2(1.0)$ \\
\hline Poultry manure & 0 (no PPF) & $10.4(4.8)$ \\
\hline Poultry manure & $1(2.3-4.8 \mathrm{mg} / \mathrm{kg} \mathrm{PPF})$ & $89.9(2.9)$ \\
\hline Poultry manure & 3 (6.9-14.4 mg/kg PPF) & $90.6(4.2)$ \\
\hline \multicolumn{3}{|l|}{ ANOVA $F^{3}$} \\
\hline Substrate $(d f=3,6)$ & $1.04 \mathrm{~ns}$ & \\
\hline Proportion PPF flies $(d f=2,6)$ & $79.25 * *$ & \\
\hline Substrate* proportion PPF flies $(d f=6,48)$ & $7.30 * *$ & \\
\hline
\end{tabular}

${ }^{1} \mathrm{PPF}$ concentration calculation: $0.8-1.7 \mathrm{mg}$ PPF carried by each fly, divided by the weight of the substrate, $350 \mathrm{~g}$

${ }^{2}$ Pupal mortality from samples of 100 pupae from each container

${ }^{3}$ Two-way ANOVA; ns, $P>0.05 ; * P<0.05$; $* * P<0.01$ 
Table 4 Effect of varying the proportion of PPF-treated (by forced contact) female house flies on pupal mortality, after flies were placed on wheat bran rearing medium or different animal manures for $24 \mathrm{~h}$ after exposure. Flies were placed in groups of 10 , of which $0,1,2,5$ or 10 flies were coated with PPF

\begin{tabular}{|c|c|c|}
\hline Substrate & No. PPF flies (mg/kg PPF range) ${ }^{1}$ & $\begin{array}{l}\text { Mean (SE) } \% \\
\text { pupal mortality }\end{array}$ \\
\hline Bran medium & 0 (no PPF) & $10.5(1.7) \mathrm{a}$ \\
\hline Bran medium & $1(2.3-4.8 \mathrm{mg} / \mathrm{kg}$ PPF $)$ & $40.1(11.0) \mathrm{ab}$ \\
\hline Bran medium & $2(4.6-9.6 \mathrm{mg} / \mathrm{kg} \mathrm{PPF})$ & $45.7(13.9) \mathrm{ab}$ \\
\hline Bran medium & 5 (11.5-24 mg/kg PPF) & $49.0(14.9) \mathrm{ab}$ \\
\hline \multirow[t]{2}{*}{ Bran medium } & 10 (23-48 mg/kg PPF) & $76.5(7.0) \mathrm{b}$ \\
\hline & Statistical test results & $F_{4,20}=4.808 * *$ \\
\hline Cow manure & 0 (no PPF) & $3.6(1.4) \mathrm{a}$ \\
\hline Cow manure & $1(2.3-4.8 \mathrm{mg} / \mathrm{kg} \mathrm{PPF})$ & $16.2(8.9) \mathrm{b}$ \\
\hline Cow manure & $2(4.6-9.6$ mg/kg PPF) & $21.1(4.8) b$ \\
\hline Cow manure & $5(11.5-24 \mathrm{mg} / \mathrm{kg} \mathrm{PPF})$ & $64.1(9.5) \mathrm{c}$ \\
\hline \multirow[t]{2}{*}{ Cow manure } & 10 (23-48 mg/kg PPF) & $91.5(3.1) \mathrm{c}$ \\
\hline & Statistical test results & $F_{4,20}=22.478 * *$ \\
\hline Poultry manure & 0 (no PPF) & $4.1(1.2) \mathrm{a}$ \\
\hline Poultry manure & $1(2.3-4.8 \mathrm{mg} / \mathrm{kg} \mathrm{PPF})$ & $77.4(5.6) \mathrm{b}$ \\
\hline Poultry manure & $2(4.6-9.6 \mathrm{mg} / \mathrm{kg} \mathrm{PPF})$ & $81.7(4.8) \mathrm{bc}$ \\
\hline Poultry manure & 5 (11.5-24 mg/kg PPF) & $86.8(5.9)$ bc \\
\hline \multirow[t]{2}{*}{ Poultry manure } & 10 (23-48 mg/kg PPF) & $95.5(3.4) \mathrm{cd}$ \\
\hline & Statistical test results & $F_{4,20}=40.947 * *$ \\
\hline \multicolumn{3}{|l|}{$\mathrm{KW} \chi^{2(3)}$} \\
\hline Substrate $(d f=2)$ & & $8.331 *$ \\
\hline Proportion PPF flies $(d f=4)$ & & $44.280 * *$ \\
\hline
\end{tabular}

${ }^{1} \mathrm{PPF}$ concentration calculation: $0.8-1.7 \mathrm{mg}$ PPF carried by each fly, divided by the weight of the substrate, $350 \mathrm{~g}$

${ }^{2}$ Means within columns followed by the same letter are not significantly different at $P=0.05$ (Tukey's HSD)

${ }^{3}$ Kruskal-Wallis; ns, $P>0.05 ; * P<0.05 ; * * P<0.01$ flies were treated, compared to mortality in the controls. Efficacy in poultry manure was particularly high even when only one fly out of 10 was treated with PPF $(2.3-4.8 \mathrm{mg} / \mathrm{kg}$ PPF in the manure) (Table 4).

When flies were allowed to move freely in a cage and visit the manure on a free-choice basis, pupal mortality in cow manure remained very low even in the groups with half of the flies coated (Fig. 2). In contrast, pupal mortality in the poultry manure was significantly and substantially higher in the treated groups compared to the control group and to cow manure, reaching over $90 \%$ mortality already when only $20 \%$ of the flies (four treated flies out of 20 flies total) were coated (Fig. 2). In this experiment, we could not assess the concentration of PPF in the substrate, because flies were not confined to the substrate and have likely shed some of the PPF elsewhere.

\section{Discussion}

The present studies have expanded the range of insect pests that may be suitable targets for the autodissemination approach, from mosquitoes that breed in containers or small water bodies (Caputo et al. 2012; Wang et al. 2014; Tuten et al. 2016; Unlu et al. 2017; Akhoundi et al. 2018; Swale et al. 2018), to house flies that breed in a variety of substrates such as animal manures and rotting vegetation. Overall, we found that the effectiveness of autodissemination for house fly control was affected by fly population size, the proportion of the population that was treated, manure type and location and delivery method.

We started by evaluating various PPF formulations (see supplementary material) and then tested the persistence of the selected formulation on treated flies. We found that even when flies were allowed to oviposit $6 \mathrm{~h}$ after they were exposed to PPF, the mortality rates of their progeny remained high (70-95\%), depending on exposure method. The difference between the results of the two exposure methods is likely due to a longer exposure time of $5-10 \mathrm{~min}$ in the treated tube apparatus compared with $3 \mathrm{~min}$ in the Petri dish, which resulted in a higher amount of PPF acquired in the tubes. These results corroborate previous research (Geden and Devine 2012; Biale et al. 2017) about the effectiveness of PPF for controlling house flies, at least under laboratory conditions. Our results suggest that treated flies retain enough dust to treat oviposition sites on the day of 
Fig. 2 Effect of different proportions of coated house flies females $(0,4,10$ females out of 20 ; in poultry manure, a treatment of 2 females was included as well), on the percentage of pupal mortality (mean \pm S.E) in small cages. In each manure type, treatments marked by a different letter are significantly different (One-way ANOVA, Tukey's HSD). Numbers in parentheses refer to thenumber of cages (replicates)

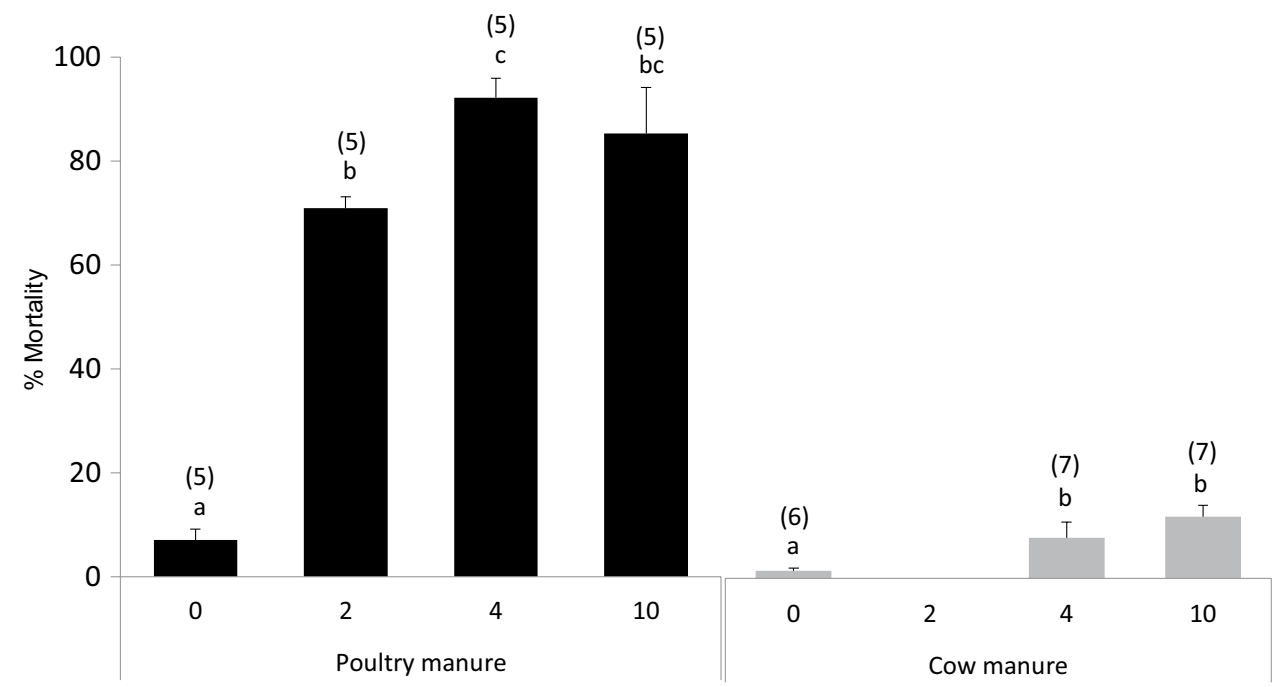

No. of treated females their treatment. Moreover, our dust retention results compare favorably with those of Gaugler et al. (2012), who found that the amount of PPF on female Aedes albopictus declined by $50 \%$ by $6 \mathrm{~h}$ post-exposure. Much of the loss is presumably due to mechanical dislodging from the insects as they fly and move about, and grooming undoubtedly plays a role (Zhukovskaya et al. 2013). Under field conditions, additional factors can be expected to reduce availability of PPF on the desired target sites. Sunlight in particular can cause substantial degradation in both aqueous and soil substrates (Sullivan and Goh 2008).

Results of the autodissemination test in indoor cages were encouraging. In the absence of other objects to visit except the cage boundaries and the baited autodissemination device, many of the flies were attracted to the bait, landed on the PPF-treated mesh and carried sufficient PPF to the oviposition substrate. However, results in the field tests contrasted sharply with the indoor cages assays where pupal mortality was never above $29.8 \%$. There are several possible explanations for the comparatively poor performance of the devices in the field. First, the greater mobility of treated flies in the field could have accelerated the loss of PPF powder from treated flies to wind, flight or contact with other objects or animals. Similar effects were observed with Aedes albopictus (Skuse), where pupal mortality due to mosquitoes carrying PPF powder dropped from $100 \%$ in an indoor arena to $57 \%$ in a greenhouse trial (Wang et al. 2014). Second, the autodissemination devices may not have been attractive enough for the flies under field conditions, where there are ample competing food sources, odors and resting sites around them. While conducting these assays, we had many opportunities to observe the response of flies to the devices. Wild flies on the Nebraska dairies, where there was a wide variety of food sources and resting sites, appeared reluctant to alight on the PPF-treated fabric. Flies were often observed to approach and fly around the devices, but only a small number actually landed. The design of the device was revamped for the California tests in an attempt to compel flies to exit a cone through a PPF-treated exit tube. In practice, we observed only a handful of flies that did so. Rather, flies were observed circling the baited pan and entering the cone, but generally either fell into the bait or exited the cone from below rather than using the PPF-lined exit tube at the top.

A third and related possibility is that the devices are not treating a sufficiently high proportion of the wild population to deliver effective control. We therefore decided to test the feasibility of an alternative method: Instead of trying to lure flies to contact PPF baits, we asked whether coating flies actively (either in a laboratory rearing facility or flies captured in situ) and then releasing them would provide sufficient control. This approach would be technically and economically feasible if a low proportion of treated flies released will transfer sufficient PPF to oviposition sites (where many untreated flies oviposit as well) to be effective. Therefore, we tested in the laboratory the proportion of flies that need to be treated (and the quantity of PPF they carry) to provide control in different animal manures.

In tests with both USA and Israeli house flies in a laboratory setting, only $10-20 \%$ of the flies needed to be treated to achieve high levels of control in poultry manure. We observed that treated flies carried 2.2-4.8 mg of powder/treated fly and that most of that was "lost" by the flies at the conclusion of the tests. If all of the powder were transferred to the media, then $20 \%$ treated flies correspond to $2.3-9.6 \mathrm{mg} / \mathrm{kg}$ PPF in the substrate (Tables 3, 4). Although the actual amount transferred was presumably less than $100 \%$, it allows for approximate comparisons to concentrations used in the previous work. In 
a previous study, we found that this range of concentrations resulted in $100 \%$ pupal mortality when applied directly to the substrate (Biale et al. 2017). Curiously, tests with Israeli manure and flies indicated relatively poor performance on cow manure, and results with USA manure and flies showed lower efficacy on horse manure. In a previous study, we noted that Israeli house flies have a somewhat higher tolerance for PPF than flies collected in the USA (Biale et al. 2017). We also observed that PPF efficacy was much lower in cattle manure than in wheat bran diet. Differences in performance on different manure types may be a complex matter, as animal diet, moisture, texture, $\mathrm{pH}$, microflora, as well as environmental conditions could affect the degradation rate of PPF (Sullivan and Goh 2008; Liu et al. 2017; Shiell 2015). Our results indicate that poultry systems may hold more promise for use of PPF.

Is autodissemination a practical method for controlling house flies? If we look at the proportion of PPF-treated flies and the resulting effects, then the answer may be yes, because 10-20\% treated flies provided adequate control, although it depended on manure type. However, the volume of manure should also be taken into account: One treated fly yielded good control in manure volumes of $\sim 0.51$ in our laboratory experiments; therefore, theoretically, about 2000 treated flies would be required for $1 \mathrm{~m}^{3}$ (=1000 l) of manure. This sounds a like a lot, but total fly density should also be taken into account, because in a situation of high fly densities more flies will visit the autodissemination devices, as was exemplified in the study of Unlu et al. (2017) on Aedes albopictus. Further field research is required on this topic, with emphasis on several topic areas: (1) Test the effects of treated flies/ manure volume ratio on control rates, in the field; (2) test the feasibility of autodissemination approach on farms, especially poultry operations; (3) improve baiting systems in order to attract more flies under field conditions; (4) evaluate more formula components, such as electrostatic powders (Baxter et al. 2008) or even other IGRs (e.g., Swale et al. 2018); (5) test autodissemination approaches (either passive or active) in urban habitats (e.g., garbage dumps and other municipal waste facilities), where autodissemination might be a practical way to apply PPF.

To conclude, the current work shows the potential as well as some pitfalls in controlling house flies using autodissemination methods, and highlights the need for further research. Given the low cost, potential efficacy and environmental safety advantages of this approach, further work in this area is warranted.

\section{Author contributions}

$\mathrm{HB}, \mathrm{EC}$ and $\mathrm{CG}$ conceived and designed research. $\mathrm{HB}$ and $\mathrm{CG}$ conducted experiments. $\mathrm{HB}$ and $\mathrm{CG}$ analyzed data. HB, EC and CG wrote the manuscript. All authors read and approved the manuscript.

Acknowledgements We thank Mr. Andy Resnick (Agan-Adama, Israel) for supplying us with technical PPF (on the Israeli side). Author CJG thanks Dana Johnson and Roxie White for assisting with the bioassays in the USA. The research was supported by the United States-Israel Binational Agricultural Research and Development Fund (BARD), Grant \# 4701-14R to CJG and EC.

\section{Compliance with ethical standards}

Conflict of interest All authors declare they have no conflict of interest.

Ethical approval This article does not contain any studies with human participants or animals performed by any of the authors.

\section{References}

Akhoundi M, Jourdain F, Chandre F, Delaunay P, Roiz D (2018) Effectiveness of a field trap barrier system for controlling Aedes albopictus: a "removal trapping" strategy. Parasit vectors 11:101

Baxter IH, Howard N, Armsworth CG, Barton LE, Jackson C (2008) The potential of two electrostatic powders as the basis for an autodissemination control method of Plodia interpunctella (Hübner). J Stored Prod Res 44:152-161

Bensebaa F, Kilani-Morakchi S, Aribi N, Soltani N (2015) Evaluation of pyriproxyfen, a juvenile hormone analog, on Drosophila melanogaster (Diptera: Drosophilidae): insecticidal activity, ecdysteroid contents and cuticle formation. Eur J Entomol 112:625-631

Biale H, Geden CJ, Chiel E (2017) Effects of pyriproxifen on wild populations of the house fly, Musca domestica, and compatibility with its principal parasitoids. Pest Manag Sci 73:2456-2464

Caputo B, Ienco A, Cianci D, Pombi M, Petrarca V, Baseggio A, Devine GJ, Della Torre A (2012) The "auto-dissemination" approach: a novel concept to fight Aedes albopictus in urban areas. PLoS Negl Trop Dis. https://doi.org/10.1371/journ al.pntd.0001973

Devine GJ, Perea EZ, Killeen GF, Stancil JD, Clark SJ, Morrison AC (2009) Using adult mosquitoes to transfer insecticides to Aedes aegypti larval habitats. Proc Natl Acad Sci U S A 106:11530-11534

Dowd PF, Vega FE (2003) Autodissemination of Beauveria bassiana by sap beetles (Coleoptera: Nitidulidae) to overwintering sites. Biocontrol Sci Technol 13:65-75

Durel L, Estrada-Peña A, Franc M, Mehlhorn H, Bouyer J (2015) Integrated fly management in European ruminant operations from the perspective of directive 2009/128/EC on sustainable use of pesticides. Parasitol Res 114:379-389

El-Sufty R, Al Bgham S, Al-Awash S, Shahdad A, Al Bathra A (2011) A trap for auto-dissemination of the entomopathogenic fungus Beauveria bassiana by red palm weevil adults in date palm plantations. Egypt J Biol Pest Control 21:271-276 
Farkas R, Hogsette J, Papp L, Darvas B (2000) Control possibilities of filth-breeding flies in livestock and poultry production. Man Palearct Diptera 1:889-904

Furlong MJ, Pell JK, Choo OP, Rahman SA (1995) Field and laboratory evaluation of a sex pheromone trap for the autodissemination of the fungal entomopathogen Zoophthora radicans (Entomophthorales) by the diamondback moth, Plutella xylostella (Lepidoptera: Yponomeutidae). Bull Entomol Res 85:331-337

Gaugler R, Suman D, Wang Y (2012) An autodissemination station for the transfer of an insect growth regulator to mosquito oviposition sites. Med Vet Entomol 26:37-45

Geden CJ, Devine GJ (2012) Pyriproxyfen and house flies (Diptera: Muscidae): effects of direct exposure and autodissemination to larval habitats. J Med Entomol 49:606-613

Geden CJ, Hogsette JA (2001) Research and extension needs for integrated pest management for arthropods of veterinary importance. In: Proceedings of a workshop in Lincoln, Nebraska. http://digit alcommons.unl.edu/usdaarsfacpub/1039/. Accessed Mar 2018

Ishaaya I, Degheele D (1998) Insecticides with novel modes of action: an overview. In: Ishaaya I, Degheele D (eds) Insecticides with novel modes of action mechanisms and application, 1st edn. Springer, Berlin, Heidelberg, New York, pp 1-24

Kasai S, Sun H, Scott JG (2017) Diversity of knockdown resistance alleles in a single house fly population facilitates adaptation to pyrethroid insecticides. Insect Mol Biol 26:13-24

Kaufman PE, Nunez SC, Mann RS, Geden CJ, Scharf ME (2010) Nicotinoid and pyrethroid insecticide resistance in houseflies (Diptera: Muscidae) collected from Florida dairies. Pest Manag Sci 66:290-294

Khan HAA, Shad SA, Akram W (2013) Resistance to new chemical insecticides in the house fly, Musca domestica L., from dairies in Punjab, Pakistan. Parasitol Res 112:2049-2054

Klein MG, Lacey LA (1999) An attractant trap for autodissemination of entomopathogenic fungi into populations of the Japanese beetle Popillia japonica (Coleoptera: Scarabaeidae). Biocontrol Sci Technol 9:151-158

Liu H, Wang P, Zhou Z, Liu D (2017) Enantioselective dissipation of pyriproxyfen in soils and sand. Chirality 29:358-368

Malik A, Singh N, Satya S (2007) House fly (Musca domestica): a review of control strategies for a challenging pest. J Environ Sci Health Part B 42:453-469

Moslim R, Kamarudin N, Wahid MB (2011) Trap for the auto dissemination of Metarhizium Anisopliae in the management of rhinoceros beetle, Oryctes Rhinoceros. J Oil Palm Res 23:111-117

Sanchez-Arroyo, H, Capinera JL (2014) House fly, Musca domestica Linnaeus. Dissertation, University of Florida
Scott JG (2017) Evolution of resistance to pyrethroid insecticides in Musca domestica. Pest Manag Sci 73:716-722

Scott JG, Leichter CA, Rinkevihc FD, Harris SA, Su C, Aberegg LC, Moon R, Geden CJ, Gerry AC, Taylor DB, Byford RL, Watson W, Johnson G, Boxler D, Zurek L (2013) Insecticide resistance in house flies from the United States: resistance levels and frequency of pyrethroid resistance alleles. Pest Biochem Physiol 107:377-384

Shiell J (2015) Manure characteristics affecting the management of house fly (Musca domestica L.) populations in duck production facilities. Dissertation, University of Guelph

Sullivan JJ, Goh KS (2008) Environmental fate of pyriproxyfen. J Pestic Sci 33:339-350

Swale RD, Li Z, Kraft ZJ, Healy K, Liu M, David MC, Liu Z, Foil DL (2018) Development of an autodissemination strategy for the deployment of novel control agents targeting the common malaria mosquito, Anopheles quadrimaculatus say (Diptera: Culicidae). PLoS Negl Trop Dis. https://doi.org/10.1371/journal.pntd.00062 59

Tunaz H (2004) Insect growth regulators for insect pest control. Turk J Agric For 28:377-387

Tuten HC, Moosmann P, Mathis A, Schaffner F (2016) Effects of pyriproxifen on Aedes japonicus development and its auto-dissemination by gravid females in laboratory trials. J Am Mosq Control Assoc 32:55-58

Unlu I, Suman DS, Wang Y, Klingler K, Faraji A, Gaugler R (2017) Effectiveness of autodissemination stations containing pyriproxyfen in reducing immature Aedes albopictus populations. Parasit Vectors. https://doi.org/10.1186/s13071-017-2034-7

Vickers RA, Furlong MJ, White A, Pell JK (2004) Initiation of fungal epizootics in diamondback moth populations within a large field cage: proof of concept for auto-dissemination. Emtomol Exp Appl 111:7-17

Wang Y, Suman DS, Bertrand J, Dong L, Gaugler R (2014) Dualtreatment autodissemination station with enhanced transfer of an insect growth regulator to mosquito oviposition sites. Pest Manag Sci 70:1299-1304

Zhukovskaya M, Yanagawa A, Forschler BT (2013) Grooming behavior as a mechanism of insect disease defense. Insects 4:609-630

Publisher's Note Springer Nature remains neutral with regard to jurisdictional claims in published maps and institutional affiliations. 